\title{
The Effects of Speed and Altitude on Wireless Air Pollution Measurements using Hexacopter Drone
}

\author{
Rami Noori ${ }^{1}$ \\ Faculty of Information Science and Technology (FTSM) \\ Universiti Kebangsaan Malaysia (UKM) ${ }^{1}$
}

\author{
Dahlila Putri Dahnil $^{2}$ \\ Center for Software Technology and Management \\ (SOFTAM) Faculty of Information Science and Technology \\ (FTSM), Universiti Kebangsaan Malaysia (UKM) ${ }^{2}$
}

\begin{abstract}
Air pollution has a severe impact on human beings and one of the top risks facing human health. The data collection near pollution sources is difficult to obtain due to obstacles such as industrial and rural areas, where sensing usually fails to give enough information about the air quality. Unmanned Aerial Vehicles (UAVs) equipped with different sensors offer new approaches and opportunity to air pollution and atmospheric studies. Despite that, there are new challenges that emerged with using UAVs, in particular, the effect of wind-generated from UAVs propellers rotation on the efficiency and ability to sense and measure gas concentrations. The results of gas measurement are affected by the propellers rotation and the wind resistance. Thus, the effect of changing UAV speed and altitude on the gas measurement both vertically and horizontally need to be performed. The aims of this paper is to propose a new mobilewireless air pollution system composed of UAV equipped with low-cost sensors using LoRa transmission. The proposed system is evaluated by studying the effect of changing altitude and speed on the measured gas concentrations CO, LPG, H2, and smoke when flying in horizontally and vertically directions. The results showed that our system is capable of measuring CO, LPG, H2, and smoke in the vertical mode in both hovering and deploying scenarios. While in horizontal mode the results showed that system can detect and measure gas concentrations at speeds less than or equal to $6 \mathrm{~m} / \mathrm{s}$. While at high speed of 8 and $10 \mathrm{~m} / \mathrm{s}$ there will be an impact on its performance and accuracy to detect the targeted gases. Also, the results showed that the LoRa shield and Radio transmitter AT9S can successfully transmit up to $800 \mathrm{~m}$ horizontally and $\mathbf{4 0 0}$ feet vertically.
\end{abstract}

Keywords-Unmanned Aerial Vehicles (UAVs); low-cost sensors; air pollution; LoRa; air quality; radio transmitter; atmosphere

\section{INTRODUCTION}

The continuous changes in ambient air that are associated with both natural and anthropogenic emissions (such as aerosols or gaseous pollutants) has a significant effect on air quality and consequently on human health [1]. Recent studies on the "Global Burden of Disease," identified air pollution as one of the top 10 risks facing human beings. Many cities have consistently violated the recommended concentration ranges of air pollutants and the direct implication of this violation is several air pollutant-related premature deaths [2], [3].

Haze is one of the most common phenomena associated to air contamination which happens almost every year within the past decades in Southeast Asia including Malaysia due to the forest fires particularly in Sumatra and Kalimantan, Indonesia
[4]. According to [5], Malaysian economic loss was around 4,471 USD per haze day and the study predicted in next 20 years, the losses will be from 1 million USD to 1.6 million USD per year. The biomass burning caucus serious air pollution and increases the haze condition [6], also considered as a major source of carbon monoxide (CO) [7]. The $\mathrm{CO}$ is one of the most hazardous air pollutants that causes severe health problems and more than 400 co-related deaths reported yearly in the U.S. [8].

However, the conventional air contamination monitoring systems (ACMS), despite being efficient and reliable for measuring a wide range of pollutants, still have some drawbacks in terms of their size, weight, and cost. One of the drawbacks is that the monitoring stations may not be able to cover all locations. Hence, there are several un-monitored locations need to be estimated [9]. These drawbacks necessitate the wide deployment of air monitoring stations [10]. Furthermore, the analysis of the data and its deployment in conventional ACMS is too slow. So, high spatial-temporal resolution with a real-time system is fundamental because of the restricted information accessibility and non-versatility of the traditional ACMS [9].

Low-cost sensors change the traditional way of measuring air pollutants [2], they can be used with higher spatial \& temporal resolutions [11]. However, the detecting range of the low-cost sensors is much lower than the traditional observing tools due to the direct interaction of the sensor surface with a small volume of the chemical compounds. Hence, a stationary sensor network is not applicable in most cases from both economical and deployment-related perspectives [12]. As a result of that, many researches have been trying to utilize mobile objects in both ground and air [13]. Mobility can fill the gap between the traditional monitoring tools and the air quality measurement models, especially in the areas without monitoring stations where the data about pollution is achieved via air quality modeling or predictions [9].

Although the mobile ground objects offer some advantages, they still have limitations, such as in industrial and rural areas where sensing usually fails to give enough information to acquire sensible measurements with the required granularity level [13]. These concerns necessitate the use of UAVs to monitor such areas [14]. UAV technology has gradually gained popularity over the years [15], and a vast amount of information has been collected for air pollution that spread across scientific and non-scientific databases [16]. It 
plays an essential role in many other fields such as food security that help to combat food insecurity due to the COVID-19 pandemic [17]. However, UAVs provide new challenges, in terms of payload capacity, power consumption and stability [10]. Also, the limitation on sensors selection which needs to be suitable and small enough to mount them on board UAVs and that may lead to select sensors with less sensitivity and selectivity [1]. Furthermore, data captured by low-cost sensors must be critically evaluated due to their heavy dependence on numerous factors, especially the impact of wind generated by the UAVs propellers rotation [10]. Also [18] shows that using UAVs for air pollution measurement can be only effective if the location point of the air sensor has been optimized. Moreover, the accurate results of gas measurement rely highly on the contribution of propellers rotation and wind resistance that need to be assessed.

In this study, we aimed to develop a mobile-wireless air pollution system to measure gases concentration such as $\mathrm{CO}$, LPG, $\mathrm{H} 2$ and smoke by developing a detection system based on low-cost sensors (subsystem-1), and an affordable and open-source UAV (subsystem-2). The system is evaluated on the effect of changing altitude and speed on gas concentration when flying horizontally and vertically. The experiment conducted is also to assess the communication range of the system stations using LoRa Shield and Radio transmitter AT9S.

\section{RELATED WORKS}

The air pollution monitoring systems and low-cost sensors are presented in this section. The existing works are grouped into three categories based on the carriers of the low-cost sensor nodes. The disadvantages of each category are highlighted in each subsection. This section is organized as follows: i) the static low-cost sensors used for air pollution measurement; ii) low-cost sensors with mobile-ground objects; and iii) low-cost sensors with mobile flying objects.

\section{A. Static Low-Cost Sensors}

The study by [19], used a micro controller-based toxic gas to detect and alert the presence of hazardous gases like LPG and propane emission. When these gases exceed their safety level, an alarm is generated and send an SMS message through GSM modem to an authorized person. Their system consists of PIC 16F877 as a Micro controller and MQ-2 and MQ-6 gas sensors. The analog signal sensed from the sensors represents the concentration of the hazardous gases and converted to digital signals through ADC in their microcontroller. The system provides fast response with accurate results which leads to faster diffusion in emergency cases. The limitations of this system is its only applicable for indoor air quality monitoring and the sensor nodes are constantly on sleep mode as there is no updating of data in the same location continuously.

The author in [20] developed a WSN for outdoor monitoring of air pollution, the designed prototype was tested on a real-time basis. The sensors capture $\mathrm{O}_{3}, \mathrm{NO}_{2}, \mathrm{CO}, \mathrm{H}_{2} \mathrm{~S}$ pollution data while the sensed data is transmitted via GPRS to the server. Solar panel is used to provide power to the stationary sensor nodes. Customized mobile and web apps are provided for making the air pollution data available to the public. The challenges facing this system is in terms of temporal-resolution when the number of deployed stations increases. The increment override the low spatial-resolution that leads to congestion in a single cellular base station that serves a large number of monitoring stations.

Another research [11] developed a low-cost air quality system known as DiracSense to measure gas pollutants that are indexed by Malaysian ambient air quality standards. They used $\mathrm{CO}-\mathrm{AF}$, OX-AF, and NO2-AF sensors that are manufactured by Alphasense. The electrochemical sensors measure $\mathrm{CO}, \mathrm{O} 3$, and $\mathrm{NO} 2$ gases. PTU300 sensor measures temperature, pressure, and relative humidity. Also, they used Raspberry $\mathrm{Pi}$ as a micro-controller. DiracSense collects, analyzes, and shares air quality data using wireless communication. An android mobile phone application was used to display the data of air quality. They calibrated the sensors by using laboratory and field test experiments. They used an adaptive neuro-fuzzy inference system (ANFIS) as the calibration model and used a multi-layer perceptron (MLP) to assess the capability of the ANFIS as the calibration model. The results showed that the ANFIS model is promising as a calibration tool due to its ability to enhance the accuracy and performance of the low-cost electrochemical sensors.

The study by [21] presented an air pollution and monitoring model that consists of Bluetooth micro controller for transferring the values of the sensors from ADC to a server, MOS (MQ-7, MQ-5) sensors, and server to save all the data collected. They also presented the ID3 algorithm to calculate the sensor values saved on the server based on probability. They proved that the model can predict the air pollution in some areas. Research [22] developed an air pollution measurement and prediction system for measuring $\mathrm{CO}$ and $\mathrm{H}_{2}$. Their system consists of Beagle bone Black as a micro controller, MOS (MQ-7, MQ-11) sensors, and GPS module for tracking the concentration of pollution. The data collected from the sensors are uploaded on Azure Cloud via Python SQL. They applied a machine learning service on the data saved in cloud for predicting the pollution. This study shows that the cloud data can be used for prediction of air pollution. The challenges facing these two systems is in terms of spatial-resolution that the number of node sensors should also be increased to cover a larger spatial resolution.

\section{B. Low Cost Sensors in Ground-based Mobile Objects}

Many researchers utilize mobile ground objects [13] for air pollution measurement to overcome drawbacks of facing static systems in terms of low spatial-temporal resolution, deployment of sensor nodes, maintenance and calibration obstacles.

In ground mobile objects, [23] presented a real-time WSNbased pollution monitoring. The sensors sense the concentration of $\mathrm{CO}, \mathrm{CO}_{2}$, and $\mathrm{O}_{2}$ gases deployed on sensor nodes that have been calibrated. The project implementation was done in the industrial area of Hyderabad city. The study deployed a multi-hop data collection algorithm while the collected air pollutant data from the designed test beds are made available onto the internet through dedicated web interface. The developed system is capable of obtaining the 
fine-grain pollution data on a real-time basis. The challenges facing this type of systems are in terms of uncontrolled or semi-controlled mobile and redundant sampling issues.

The author in [24] developed a system called Air-sense for air quality monitoring in both outdoor and indoor. Their system was designed with 4 layers. The first layer for collecting the data through the people carrying a portable Air Quality Monitoring Device (AQMD); the second for treating and formatting the data collected and transmitted through the first layer; third layer is responsible for communication between the cloud server and the smart phone and the fourth layer is responsible for analyzing and storing the data. Their AQMD consists of Arduino Pro Mini board as a micro controller, MOS (MQ-7, MQ-135) for detecting CO, and monitoring air quality and Bluetooth module HC-05 for transmitting the data from AQMD to smart phones. The study concluded that this system will encourage the citizens to be part in the crowd sensing action, which could be a backbone of any smart city. The challenges facing this type of systems in terms of spatial-to-temporal resolution trade-off (higher spatial coverage at the expense of lower temporal resolution), also low data accuracy and reliability.

The author in [25] presented a low-cost system for air quality monitoring using a vehicular sensor network. This system processes the data collected by sensors located on public vehicles. The system consists of Arduino as a microcontroller connected to MOS sensors for detecting $\left(\mathrm{NO}_{2}, \mathrm{CO}_{2}\right.$, $\mathrm{CO}$, and Ozone), as well as to measure air quality. The acquired data is transferred to a server on Raspberry Pi board through Xbee-based Access Points installed on the road.

The author in [26], suggested a low-cost portable system for air pollution monitoring by using IoT to create awareness to the public about the air quality, enabling them to make better choices regarding traveling routes or purchasing of houses in a better area.

\section{Low Cost Sensors in Flying-based Mobile Objects}

Researchers have been trying to utilize mobile flying objects such as UAVs to overcome the drawbacks facing mobile-ground systems in terms of low spatial resolution Also, it's proven that air pollution changes abruptly even at a small relative distance both horizontally and vertically [13].

In flying mobile objects, [10] presented an Air Pollutants Monitoring Using UAVs (ARIA) project, with the aim of finding a toll to measure air quality vertically at different heights. They presented an overview about their project and the low-cost air pollution measurement without the experimental results. For air pollution monitoring, they presented a system that consists of Raspberry Pi 3 as micro controller, Alpha-sense Gas sensors, and Particulate and Volatile Organic Compounds (VOCs) sensors. They suggested placing the sensors inside the drone to avoid the airstream generated from the propeller rotation, with mention of the drawbacks of this configuration which can lead to losses of signal along the wires. They stored data on an On-Board storage control unit connected with the measurement system and when the drone land off, they can download the data from the board.
The author in [8] suggested an airborne WSN system called AIRWISE for automated measurement and monitoring of ambient air pollution. The system comprised of an unmanned aerial vehicles (UAVs) and a pollution-aware wireless sensor (PAWS) network. The system was designed for monitoring of ambient air pollutants in 3D spaces without any form of human intervention. They suggested two schemes for autonomous monitoring of a 3D area of interest; their PAWS consist of Wasp mote node as a micro-controller, GPS module and integrated sensors for measuring gases concentration and air quality. The targeted gases were $\mathrm{O} 2$, $\mathrm{NH} 3, \mathrm{CH} 4$, and $\mathrm{CO} 2$.

The author in [27] presents a data acquisition system and its coupling into a UAV to facilitate air pollutants monitoring. The collected data is transmitted via RF to the ground station for processing. The results are displayed on a web page that can be accessed using any mobile device or computer. Their monitoring unit consists of UAV S500 quadcopter with the pix-hawk flight computer, Arduino, Shield for XBee antenna connection, XBee PRO S2B Antenna, and DAQ with sensors to measure air quality. The sensors used in this system are MQ7 to measure Carbon monoxide, MQ8 for Hydrogen, MQ131 for Ozone, and MQ135 for Carbon dioxide. The ground station consists of a PC, Arduino, and Receiver antenna 3DR used for monitoring the behavior of variables. The flying was stable when the load was located in the center of its frame, but the flight time decreased from 13 to 10 minutes. The results show that there is no lost in communication or interference within the range of 203 meters.

\section{PROPOSED SYSTEM}

The system developed and evaluated in this study consists of two subsystems: the air pollution detection system (subsystem-1) and the UAV (subsystem-2). Fig. 1 illustrates the methodology in developing the system.

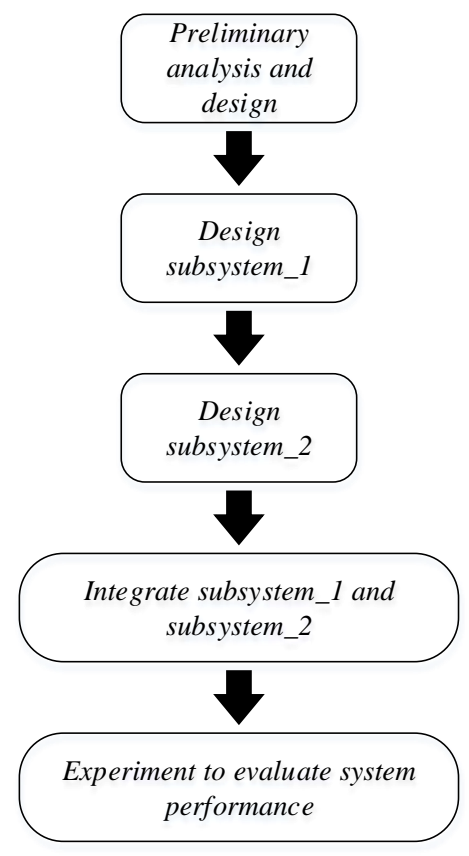

Fig. 1. Proposed Methodology. 


\section{A. Air Pollution Detection System (Subsystem_1)}

The proposed system consists of two subsytems. For subsystem_1, we used Arduino UNO over the other devices due to its power consumption and simple connectivity [1], LoRa shield is used for data transmission since it offers a long-range transmission compared to other wireless transmission techniques as shown by [28-29], and MQ sensors due to their low cost, compatible with Arduino, and their ability to sense various chemical gases.

The subsystem_1 composed of two stations, the first station is the detection station (DS_subsystem_1) to detect and measure targeted gas concentrations. The second station is the monitoring station (MS_subsystem_1) to receive and display the targeted gas concentration measurements.

The DS_subsystem_1 composed of MQ2 sensor to sense smoke and CO, MQ6 to sense LPG, and MQ8 to sense hydrogen. The sensors were coupled to the Arduino UNO R3 micro-controller and RFM LoRa Shield to facilitate wireless communication.

The MS_subsystem_1 composed of Arduino UNO R3 board with RFM LoRa Shield, connected to a PC with Arduino IDE (Integrated Development Environment) system via a USB pot for real-time visual monitoring.

\section{B. Configuring the MOS sensor (MQ2, MQ6, and MQ8)}

The As an analog sensor, the response values of the MOS gas sensor are the outputs of the analog-to-digital conversion (ADC). Based on the sensors datasheet, the resistance of the sensor (RS) will be calculate as follows [30]:

$$
R_{s}=\frac{V_{c}-V_{\text {out }}}{V_{\text {out }}} \times R L
$$

Where

$$
V_{\text {out }}=\frac{A D C * V_{c}}{1023}
$$

where $\mathrm{V}_{\mathrm{c}}$ is a micro-controller board voltage, $\mathrm{V}_{\text {out }}$ is the output voltage of the sensor in the sample space. RL is the sensor load resistance, ADC is analog-to-digital value conversion. And based on the provided chart in the MQ datasheet, $R_{S}$ in clean air is constant under standard temperature \& humidity. The Rs/R0 ratio in clean air is 9.8 as described in the datasheet. After calibrating the sensor by placing it in clean air and getting the R0 value by dividing it with the Rs/R0 value in clean air, the targeted gas can be sensed using the Rs/R0 ratio. To calculate the concentration of the targeted gas in ppm, the datasheets provided the sensitivity characteristics of each sensor with ppm (gas concentration) as $\mathrm{x}$-axis and RS/RO as y-axis. So the curve of the particular gas in the sensitivity characteristics of each sensor is used to calculate the slope [31] as follows:

$$
\text { Slope }=\frac{(Y 2-Y 1)}{(X 2-X 1)}
$$

Where $\mathrm{X} 1$ is the logarithm of the first point for targeted gas curve in $\mathrm{X}$-axis (PPM), $\mathrm{X} 2$ is the logarithm of the last point for targeted gas curve in $\mathrm{X}$-axis(PPM), Y1 is the logarithm of the first point for targeted gas curve in $y$ $\operatorname{axis}(\mathrm{RS} / \mathrm{RO})$, and $\mathrm{Y} 2$ is the logarithm of the last point for aimed gas curve in $\mathrm{y}$-axis(RS/RO). The slope of each MOS sensor (MQ2, MQ6, and MQ8) was calculated separately.

Then, we calculated the concentration of the targeted gas in ppm from:

Gas Concentration $=\frac{\left(\frac{R_{s}}{R_{o}}-Y 1\right)}{(\text { Slope }+X 1)}$

\section{Unmanned Aerial Vehicle (Subsystem_2)}

Drones are built for mobile and data-gathering capability. It can be recognized as a flying robot, which can be flown autonomously without any human interaction via softwarecontrolled flight plans or can be remotely controlled [32]. The flying mode makes it easier to reach nodes in a timely manner and also makes it easy to hover and collect data at specific nodes [10]. The Hexacopter drone is chosen in our design as it has a large payload capacity of more than 2 kilogram payload; it also has better manoeuvrability and in-flight stability in comparison to quadrotors. This made them ideal for UAVs and studies on air quality where there is a need to carry various sensors and sustain a fixed in-flight position.

Our subsystem_2 consists of two stations, Hexacopter drone (HD_subsystem_2) and UAV control station (CS_subsystem_2) as shown in Fig. 2. The purpose of the CS_subsystem_2 is for communicating wirelessly with the HS_subsystem_2 via a Radio Controller (RC) or a PC with a mission planner application connected to a Telemetry Radio. The UAV kits in this project are customized based on their functionalities and capabilities as shown in Table I. The UAV are self-assembled from scratch by studying all parts and communicating from the supplier of drone experts.

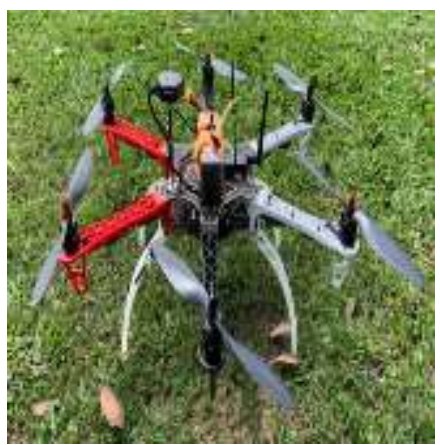

(a) Hexacopter Drone.

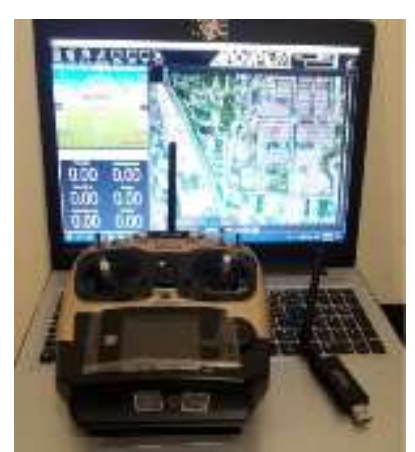

(b) UAV Control Station.
Fig. 2. UAV Stations. 
TABLE I. UAV KITS

\begin{tabular}{|c|c|c|}
\hline Model & Frame & Description \\
\hline $\begin{array}{l}\text { DJI F550 } \\
\text { frame }\end{array}$ & & $\begin{array}{l}\text { Hexacopter drone is strong } \\
\text { enough to carry loads. They are } \\
\text { built with an increased number } \\
\text { of motors; hence, they are } \\
\text { relatively stable in-flight, and } \\
\text { safer with } 6 \text { motors at } 120^{\circ} \\
\text { apart, whereby flight can be } \\
\text { maintained even if one fails }\end{array}$ \\
\hline $\begin{array}{l}\text { Radiolink } \\
\text { Pixhawk }\end{array}$ & & $\begin{array}{l}\text { PIXHAWK is an open source } \\
\text { flight controller made by Radio } \\
\text { link; it has less interference of } \\
\text { inner components, less noise, } \\
\text { safety while flying, more } \\
\text { accurate compass, and supports } \\
\text { various flight modes. }\end{array}$ \\
\hline $\begin{array}{l}\text { Radiolink } \\
\text { M8N GPS } \\
\text { SE100 }\end{array}$ & & $\begin{array}{l}\text { Radiolink M8N GPS is } \\
\text { compatible with all the open } \\
\text { source flight controllers its } \\
\text { accuracy is } 50 \text {-centimeter } \\
\text { position and positions } 20 \\
\text { satellites within } 6 \text { seconds at } \\
\text { open ground. It is capable of } \\
\text { valley station-keeping; Max } \\
\text { height is } 50000 \text { m and Max } \\
\text { speed is } 515 \mathrm{~m} / \mathrm{s} \text {. }\end{array}$ \\
\hline $\begin{array}{l}\text { Radiolink } \\
\text { AT9S } \\
\text { Transmitter } \\
\text { with R9DS } \\
\text { Receiver }\end{array}$ & & $\begin{array}{l}\text { This is an affordable radio } \\
\text { system with a range of } 900 \mathrm{~m} \\
\text { on the ground and } 1500 \mathrm{~m} \text { in } \\
\text { air (environment-dependent). It } \\
\text { includes a } 2.8 \text { inches LCD } \\
\text { screen that can show a real- } \\
\text { time data telemetry, such as } \\
\text { GPS, SPEED, voltage etc. and } \\
\text { it is suitable for all } \\
\text { multicopters, boats, and cars }\end{array}$ \\
\hline $\begin{array}{l}\text { FPV Radio } \\
\text { Telemetry }\end{array}$ & & $\begin{array}{l}\text { used to receive a Real-time data } \\
\text { about drone while its flying } \\
\text { into the mission planner } \\
\text { software in pc. }\end{array}$ \\
\hline $\begin{array}{l}(2212900 \mathrm{kv}) \\
\text { Brushless } \\
\text { Motor and "9" } \\
\text { Propeller }\end{array}$ & & $\begin{array}{l}\text { Fig. } 1 . \quad \text { The feature of the } \\
\text { motor is light weight, extreme } \\
\text { torque, low current and low } \\
\text { temperature }\end{array}$ \\
\hline $\begin{array}{l}\text { Hobbywing } \\
20 \text { A ESC }\end{array}$ & & $\begin{array}{l}\text { The electronic speed controller } \\
\text { for translating a pilot's controls } \\
\text { into specific instructions to be } \\
\text { transmitted to the motors for } \\
\text { movement control. Hobbywing } \\
20 \mathrm{~A} \text { ESC is designed especially } \\
\text { for multi-copters; It is } \\
\text { compatible with various flight- } \\
\text { control systems and lightly } \\
\text { weight } 14 \mathrm{~g}\end{array}$ \\
\hline $\begin{array}{l}\text { Imax B6AC } \\
\text { Charger }\end{array}$ & & $\begin{array}{l}\text { This is a versatile and fast } \\
\text { battery charger, balancer, and } \\
\text { discharger. It is compatible } \\
\text { with different types of batteries. } \\
\text { It is equipped with an internal } \\
\text { independent Li-battery balancer } \\
\text { for ensuring balanced charging } \\
\& \text { discharging of } 2-6 \text { cells. }\end{array}$ \\
\hline
\end{tabular}

\section{Integration of Subsystem 1 and Subsystem 2}

The best location to place the DS_subsystem_1 is by considering the stability of the drone at the bottom of Hexacopter (HS_subsystem_2) as shown in Fig. 3. In order to achieve drone stability during flying and hovering mode, as well as to decrease the effect of the wind generated by the propellers, we placed it as far as possible from the propellers (28 cm from propellers) with an extension to $5 \mathrm{~cm}$ from the bottom of the Hexacopter drone. This is also to ensure safety of the DS_subsystem _ 1 by using landing skid in case of falldown or land-off. By integrating both subsystems we achieved our first goal and developed a mobile wireless air pollution system which consist of two stations: mobile station (DS_subsystem_1 and HD_subsystem_2) and ground station (MS_subsystem_1 and CS_subsystem_2).

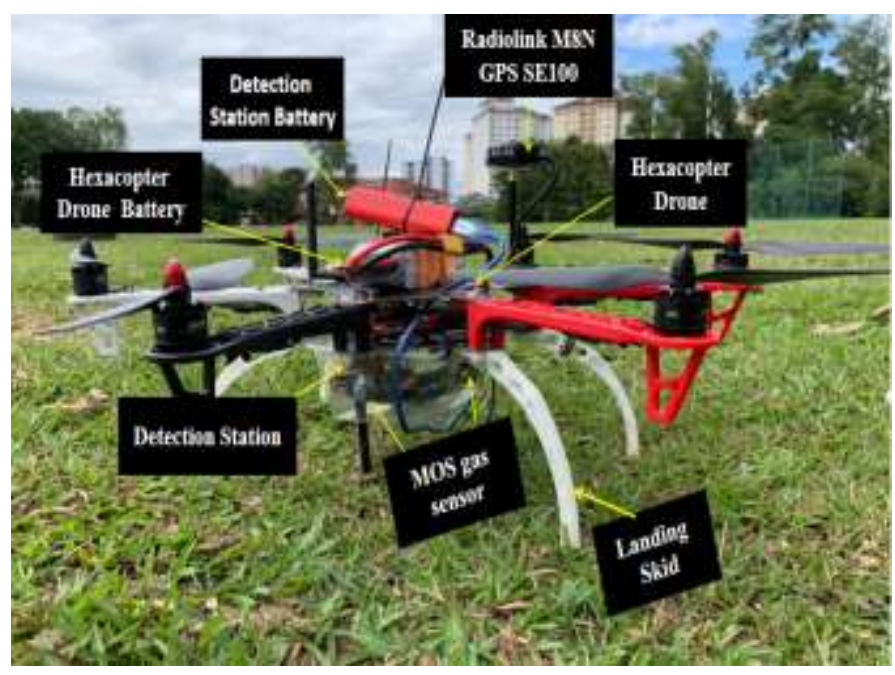

Fig. 3. Mobile Station.

\section{SySTEM EVALUATION}

In this study, three types of experiments were conducted to evaluate the effect of changing altitude and speed on the system. It detected and measured identified gases and assessed the communication range of the system stations. The experiments were performed as follows: i) To measure the range of wireless communication between the system stations (mobile and ground stations). ii) To evaluate the performance of the mobile station to detect and measure identified gas in vertical mode. iii) To evaluate the performance of the mobile station to detect and measure identified gas in horizontal mode.

\section{A. Range of Wireless Communication}

We tested the range of wireless communication of the system by flying the mobile station in an open field to the allowable maximum range according to the safety guidelines. The experiment was conducted to:

1) Examine the horizontal and vertical range of the mobile station to communicate with the ground station manually by Radio transmitter AT9S (RC) and autopilot by Radio telemetry with mission planner software. 
2) Examine the horizontal and vertical range of the mobile station to transmit ( $\mathrm{CO}, \mathrm{H} 2, \mathrm{LPG}$, and smoke) readings by LoRa Shield.

\section{B. Vertical Evaluation}

The experiments were conducted to evaluate the effect of changing altitude and speed on the mobile station performance to detect and measure targeted gas, with the following scenarios:

1) Hovering mode, the first readings were taken at one identified spot at ground level. After recording a number of packets, we raised the mobile station to $5 \mathrm{~m}$. Then the $\mathrm{RC}$ was changed into hovering mode to stabilize it at its position and altitude. Then the level was increased to $10 \mathrm{~m}$ and the measurements are recorded. The same steps are repeated on subsequent level as shown in Fig. 4.

2) Deploying mode, the initial same spot was used as described on previous experiment. The mobile station takes off from the ground to $20 \mathrm{~m}$ altitude at different speeds ranging (210) $\mathrm{m} / \mathrm{s}$ with a $2 \mathrm{~m} / \mathrm{s}$ step size as shown in Fig. 5.

\section{Horizontal Evaluation}

Experiments were carried out to evaluate the effect of changing speed on the mobile station performance to detect and measure identified gas. The experiments were set up by a flight plan installed to mobile station through the ground station (using mission planner and Radio telemetry). The flight plan was conducted by using 4 way-points as shown in Fig. 6. The way-points were as follows:

1) The first point was located above the ground station, for the mobile station to take off. After the mobile station took off at $15 \mathrm{~m}$ altitude, it flew at speed that was set through (WPNAV_SPEED in mission planner software) towards the second point.

2) The second point was located at distance of $150 \mathrm{~m}$ from the ground station. When the mobile station reaches this point, the drone hovered for 10 seconds. The gas readings received during these 10 seconds will be ignored in our measurements.

3) The third point had the same location as the second point. At this point, the "Do-change-speed "command was used; to change the mobile station speed to $2 \mathrm{~m} / \mathrm{s}$, then the mobile station flew towards the fourth point. The mobile station speed changed for the comparison purpose.

4) The fourth point was located at the ground station, where the mobile station landed.

The purpose of using this method was to ensure that the mobile station will fly at the same path in nearly same time at two different speeds, which were:

a) From first to second point, we tested different speeds ranging $(2-10) \mathrm{m} / \mathrm{s}$ with a $2 \mathrm{~m} / \mathrm{s}$ step size, to evaluate their impact on the mobile station performance to detect and measure targeted gas.

b) From third to fourth point, we used the fixed speed in the experiment $(2 \mathrm{~m} / \mathrm{s})$.

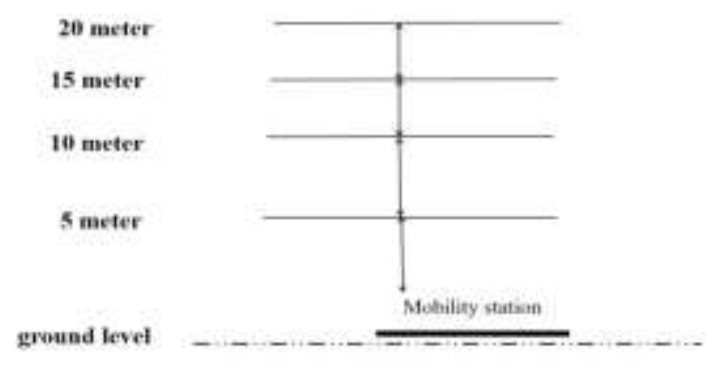

Fig. 4. Hovering Scenario.

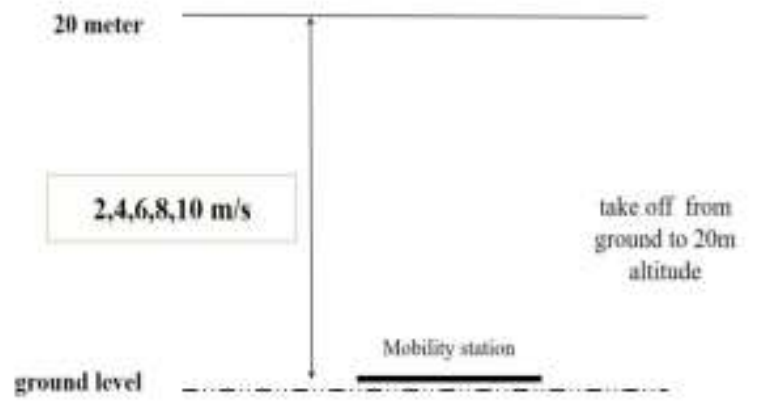

Fig. 5. Deployment Scenario.
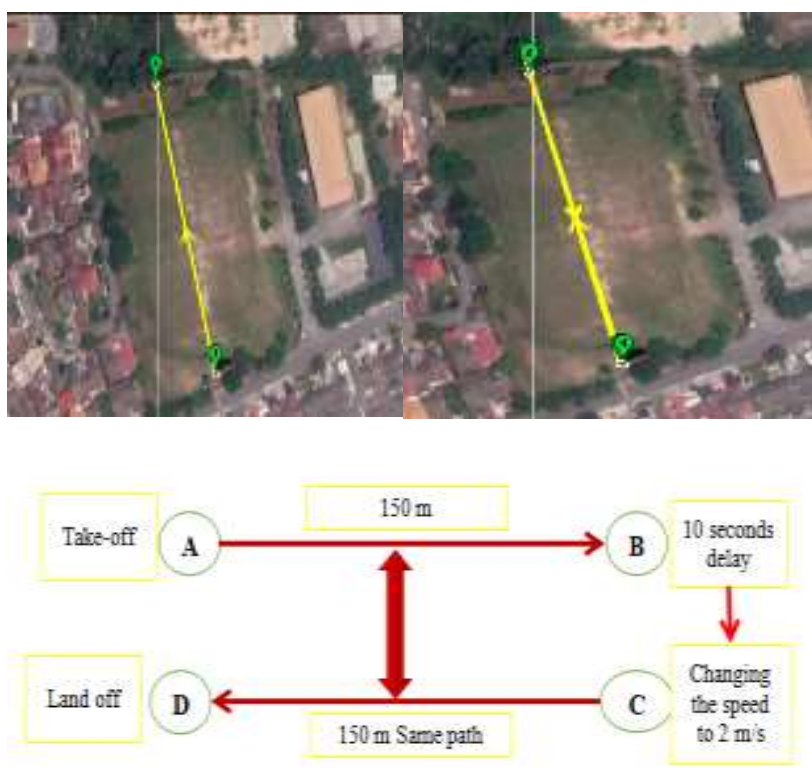

Fig. 6. Flight Plan Scenario.

\section{RESUlTS AND DISCUSSION}

The results of testing the range of wireless communication for the system stations are shown in Table II. The GPS used in the mobile station was M8N GPS SE100 and each position is accurate within (1 to 2.5$) \mathrm{m}$, and its speed is within $(0.1$ to $0.5) \mathrm{m} / \mathrm{s}$. 
TABLE II. THE WIRELESS COMMUNICATION RANGE BETWEEN SYSTEM STATIONS

\begin{tabular}{|l|l|l|}
\hline Communication method & Horizontal range & Vertical range \\
\hline Radio transmitter AT9S (RC) & 800 m horizontally & 400 feet vertically \\
\hline $\begin{array}{l}\text { Radio telemetry with mission } \\
\text { planner }\end{array}$ & $100 \mathrm{~m}$ horizontally & 100 feet vertically \\
\hline LoRa Shield & $800 \mathrm{~m}$ horizontally & 400 feet vertically \\
\hline
\end{tabular}

The average of 15 readings were taken for each gas at each altitude in the experiments for hovering mode for vertical evaluation as shown in Fig. 7. The average of 10 readings were taken for each gas at each speed for the deploying mode in the experiments as shown in Fig. 8.

Finally, for the results of the horizontal evaluation, we took the average readings for each gas in each speed experiment as shown in Fig. 9.

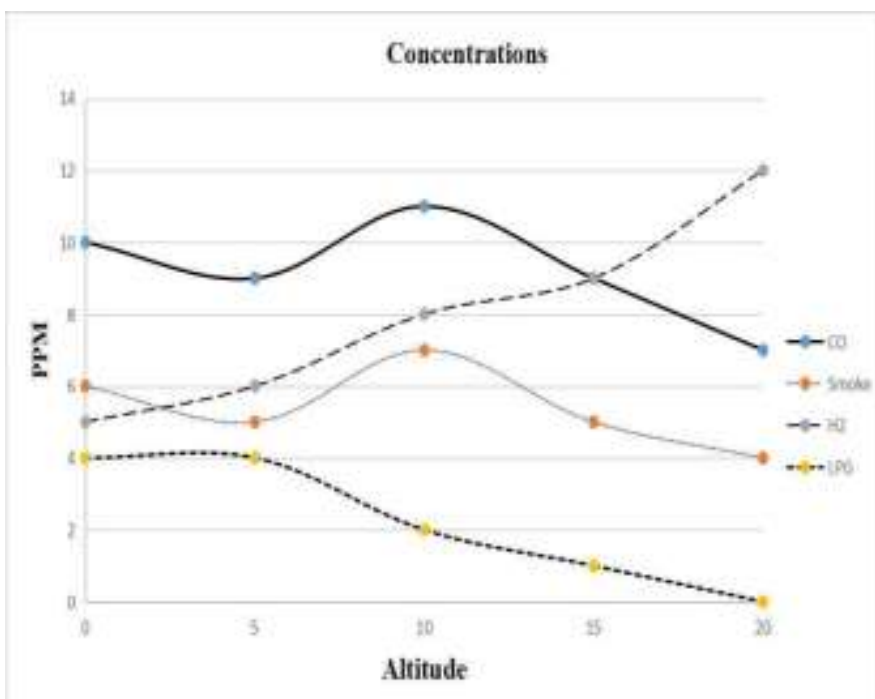

Fig. 7. Gases Concentration in Hovering Mode.

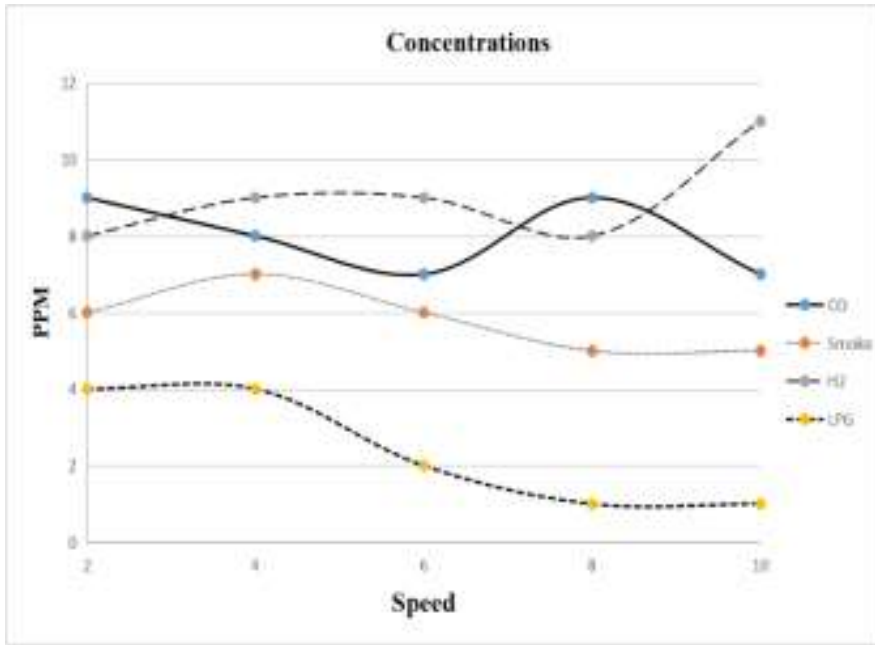

Fig. 8. Gases Concentration in Deploying Mode.

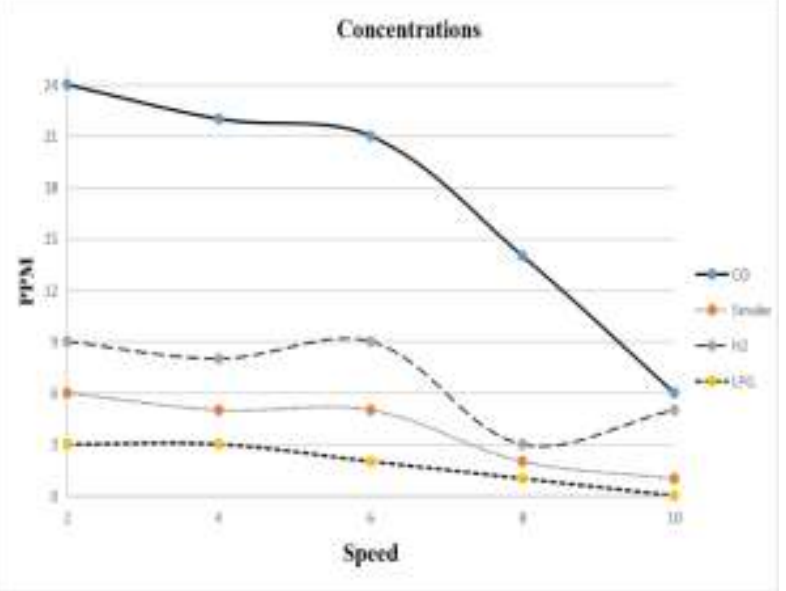

Fig. 9. Gases Concentration in Horizontal Mode.

Fig. 9 shows that there is a big change in average readings for each gas with respect to speed, especially for the $\mathrm{CO}$ gas at 8 and $10 \mathrm{~m} / \mathrm{s}$. We flew the mobile station at the same path at two different speeds. We compared the packets received at both speeds to ensure that changes in gases readings were due to changes in speed rather than the actual gas concentrations in that path. The results were as follows:

1) In the first case, the mobile station was taken from first to the second point at the following speed of $2,4,6 \mathrm{~m} / \mathrm{s}$ respectively. Then, from third to the fourth point at $2 \mathrm{~m} / \mathrm{s}$. We compared the packets received at each point. The results indicated that both gas concentrations were almost in the same range.

2) In the second case, the mobile station was taken from first to the second point at $8 \mathrm{~m} / \mathrm{s}$. Then, from third to the fourth point at $2 \mathrm{~m} / \mathrm{s}$ speed. We compared the packets received at each point as shown in Fig. 10. The results indicated a huge difference between packets received at each speed.

3) In the third case, the mobile station was taken from first to the second point at $10 \mathrm{~m} / \mathrm{s}$ speed. Then from third to the fourth point at $2 \mathrm{~m} / \mathrm{s}$ speed. We compared the packets received at each point as shown in Fig. 11. The results have indicated that there was a significant gap in gas concentrations.

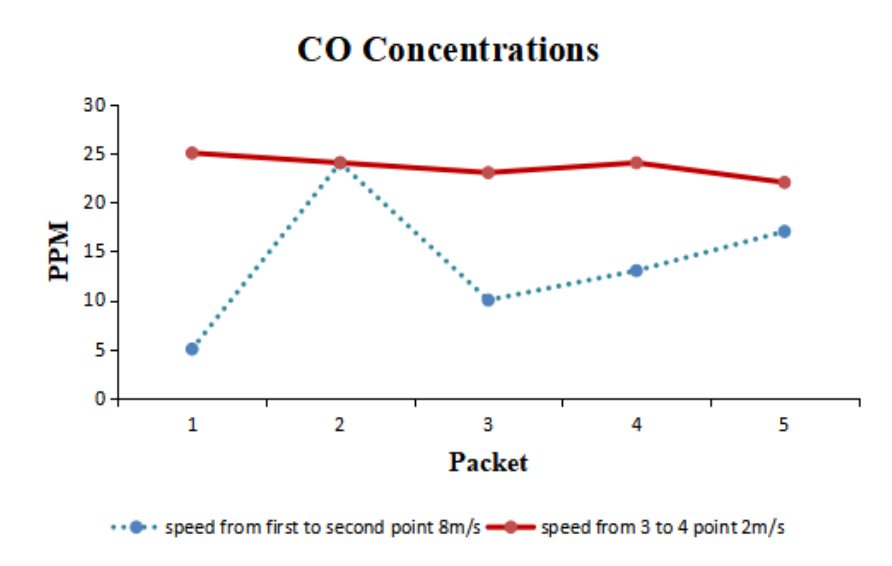



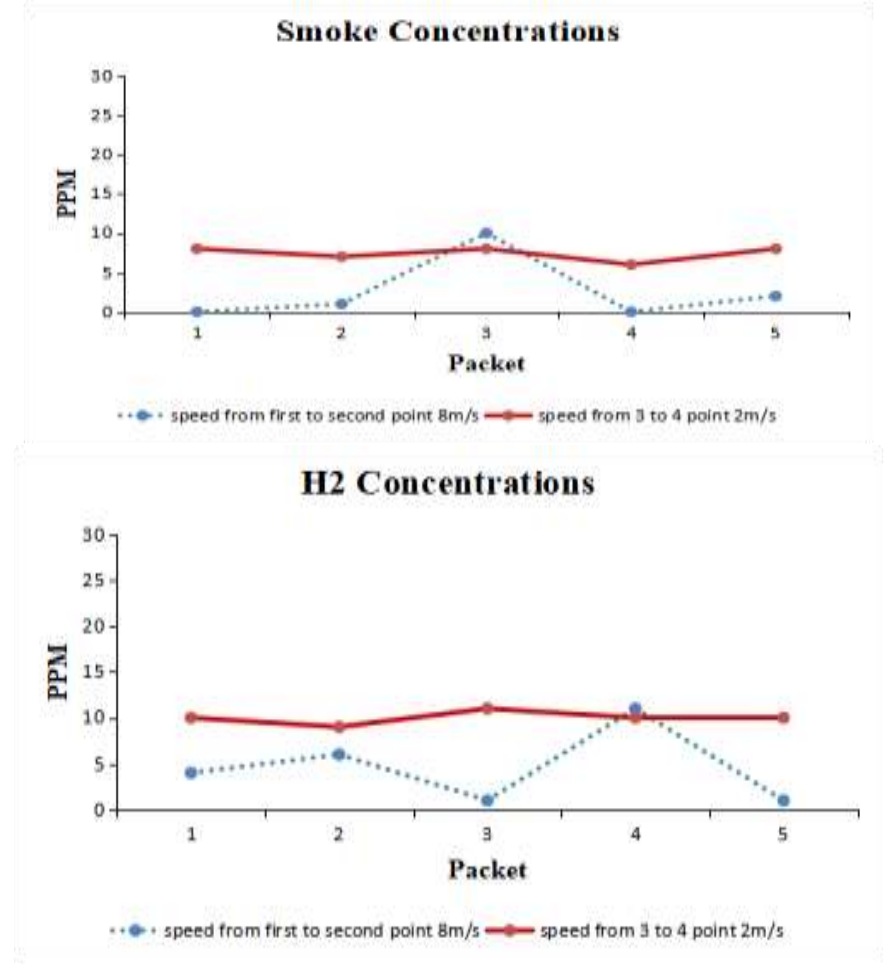

Fig. 10. Gases Concentration at $8 \mathrm{~m} / \mathrm{s}$ and $2 \mathrm{~m} / \mathrm{s}$.

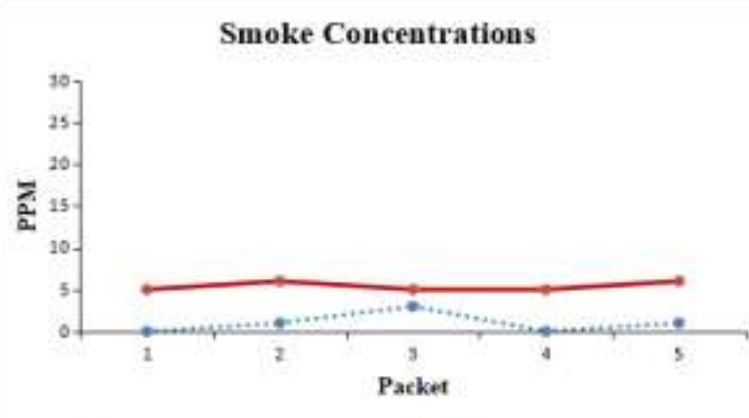

W*- speed from fres to second point $10 \mathrm{~m} / \mathrm{s} \rightarrow$ - peed tom 3 to 4 paint $2 \mathrm{~m} / \mathrm{s}$ CO Concentrations

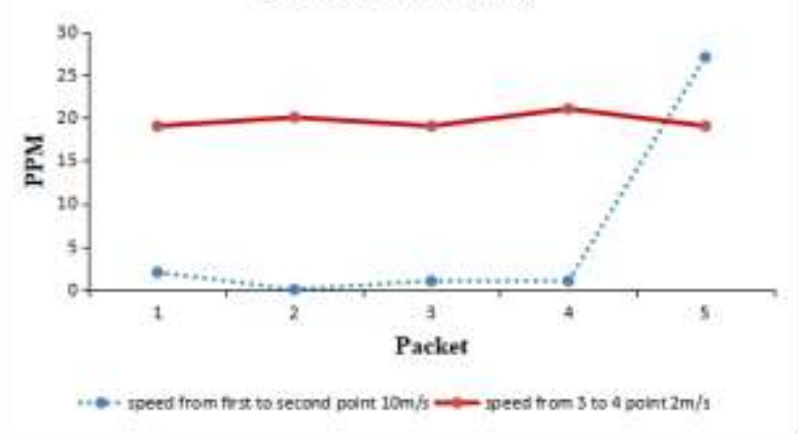

Fig. 11. Gases Concentration at $10 \mathrm{~m} / \mathrm{s}$ and $2 \mathrm{~m} / \mathrm{s}$.

\section{CONCLUSION AND FUTURE WORK}

In conclusion our system is effective to measure $(\mathrm{CO}$, LPG, H2, and Smoke) in the vertical mode in both hovering and deploying scenarios. There was no significant impact due to changes in altitude and speed to the system performance on detecting and measuring the gases concentration. In horizontal mode, the results showed that the system is effective to detect and measure gas concentrations at speeds less than or equal to $6 \mathrm{~m} / \mathrm{s}$. While at high speed $(8$ and $10 \mathrm{~m} / \mathrm{s})$ there is an impact on its performance and accuracy to detect the gases. The ineffectiveness of the mobile station performance at high speed is due to the wind generated from the rotation of the propellers in horizontal-mode. The wind generated affects the air samples around the sensors. The low-range detection for the low-cost sensors needs direct exposure to the gases. The experiments indicated that LoRa shield and RC can successfully transmit up to $800 \mathrm{~m}$ horizontally and 400 feet vertically.

Our future work will focus on measuring the wind generated from the propeller's rotation at each speed especially at high speed (8 and 10) $\mathrm{m} / \mathrm{s}$ and its effect to the air quality readings.

\section{ACKNOWLEDGMENT}

The research is financially supported by Cabaran Perdana Research Grant Scheme [Grant No.: DCP-2018-001/2], University Kebangsaan Malaysia (UKM). www.ftsm.ukm. my/softam, Faculty of Information Science and Technology.

\section{REFERENCES}

[1] T. Villa, F. Gonzalez, B. Miljievic, Z. Ristovski, and L. Morawska, “An overview of small unmanned aerial vehicles for air quality measurements: Present applications and future Prospectives", Sensors, vol. 16, no. 7, 1072, 2016.

[2] P. Kumar, L. Morawska, C. Martani, G. Biskos, M. Neophytou, S. Sabatino, M. Bell, L. Norford, and R. Britter, "The rise of low-cost sensing for managing air pollution in cities", Environment International, vol. 75, pp. 199-205, February 2015.

[3] S. Duangsuwan, and P. Jamjareekulgarn, "Development of Drone Realtime Air Pollution Monitoring for Mobile Smart Sensing in Areas with Poor Accessibility", Sensors and Materials, vol. 23, no. 7, pp. 511-520, January 2020.

[4] M. Sahani, N. Zainon, W. Mahiyuddin, M. Latif, R. Hod, M. Khan, N. Tahir, and C. Chan, "A case-crossover analysis of forest fire haze events and mortality in Malaysia", Atmospheric Environment, vol. 96, pp. 257265, October 2014.

[5] J. Montgomery, C. Reynolds, S. Rogak, and S. Green, "Financial implications of modifications to building filtration systems", Building and Environment, vol. 85, pp. 17-28, February 2015.

[6] H. Zhao, X. Zhang, S. Zhang, W. Chen, D. Tong, and A. Xiu, "Effects of Agricultural Biomass Burning on Regional Haze in China: A Review", Atmosphere, vol. 8, no. 5, May 2017.

[7] Y. Sawa, H. Matsueda, Y. Tsutsumi, J. Jensen, H. Inoue, and Y. Makino, "Tropospheric carbon monoxide and hydrogen measurements over Kalimantan in Indonesia and northern Australia during October 1997”, Geophysical research letters, vol. 26, no. 10, pp. 1389-1392, May 1999.

[8] E. Orestis, and J. Rolim, "An Airborne Wireless Sensor Network for Ambient Air Pollution Monitoring", SENSORNETS, pp. 231-239, September 2015.

[9] W. Yi, K. Lo, T. Mak, K. Leung, Y. Leung, and M. Meng, "A Survey of Wireless Sensor Network Based Air Pollution Monitoring Systems", Sensors, vol. 15, no. 12, pp. 31392-3142, December 2015.

[10] G. Bolla, M. Casagrande, A. Comazzetto, R. Moro, M. Destro, E. Fantin, G. Colombatti, A. Aboudan, and E. Lorenzini, "ARIA: Air Pollutants Monitoring Using UAVs", In 2018 5th IEEE International Workshop on Metrology for AeroSpace (MetroAeroSpace), pp. 225229, Jun 2018.

[11] K. Alhasa, M. Nadzir, P. Olalekan, M. Latif, Y. Yusup, M. Faruque, F. Ahamad, H. Hamid, K. Aiyub, S. Ali, M. Khan, A. Samah, I. Yusuff, M. 
Othman, T. Hassim, and N. Ezani, "Calibration Model of a Low-Cost Air Quality Sensor Using an Adaptive Neuro-Fuzzy Inference System”, Sensors, vol. 18, no. 12, December 2018.

[12] M. Rossi, and D. Brunelli, "Autonomous Gas Detection and Mapping with Unmanned Aerial Vehicles", IEEE Transactions on Instrumentation and Measurement, vol. 65, no. 4, pp. 765-775, December 2015.

[13] O. Alvear, N. Zema, E. Natalizio, and C. Calafate, "Using UAV-Based Systems to Monitor Air Pollution in Areas with Poor Accessibility", Journal of Advanced Transportation, August 2017.

[14] M. Dunbabin, and L. Marques, "Robots for Environmental Monitoring: Significant Advancements and Applications", IEEE Robotics \& Automation Magazine, vol. 19, no. 1, pp. 24-39, February 2012.

[15] G. Rohi, O. Ejofodomi, and G. Ofualagba, "Autonomous monitoring, analysis, and countering of air pollution using environmental drones", Heliyon, vol. 6, no. 1, e03252, January 2020.

[16] J. Burgués, and S. Marco, "Environmental chemical sensing using small drones: A review", Science of The Total Environment, vol. 748, 141172, December 2020.

[17] U. Panday, A. Pratihast, J. Aryal, and R. Kayastha, "A Review on Drone-Based Data Solutions for Cereal Crops", Drones, vol. 4, no. 3, September 2020.

[18] T. Villa, F. Salimi, K. Morton, L. Morawska, and F. Gonzalez, "Development and Validation of a UAV Based System for Air Pollution Measurements", Sensors, vol. 16, no. 12, 2202, December 2016.

[19] V. Ramya, and B. Palaniappan, "Embedded system for Hazardous Gas detection and Alerting", International Journal of Distributed and Parallel Systems (IJDPS), vol. 3, no. 3, pp. 287-300, May 2012.

[20] A. Kadri, E. Yaacoub, M. Mushtaha, and A. Abu-Dayya, "Wireless sensor network for real-time air pollution monitoring", In 2013 1st International Conference on Communications, Signal Processing, and their Applications (ICCSPA), pp. 1-5, February 2013.

[21] S. Raipure, and D. Mehetre, "Wireless sensor network-based pollution monitoring system in metropolitan cities", International Conference on Communications and Signal Processing (ICCSP), pp. 1835-1838, April 2015.

[22] N. Desai, and J. Alex, "IoT based air pollution monitoring and predictor system on Beagle bone black", International Conference on Nextgen
Electronic Technologies: Silicon to Software (ICNETS2), pp. 367-370, March 2017.

[23] M. Pavani, and P. Rao, "Monitoring Real-Time Urban Carbon Monoxide (CO) Emissions Using Wireless Sensor Networks", International Conference on Information and Communication Technology for Intelligent Systems (ICTIS), vol. 2, pp. 290-297. Springer, March 2017.

[24] J. Dutta, C. Chowdhury, S. Roy, A. Middya, and F. Gazi, "Towards Smart City: Sensing Air Quality in City based on Opportunistic Crowdsensing", In Proceedings of the 18th international conference on distributed computing and networking, no. 42, pp. 1-6, January 2017.

[25] G. Re, D. Peri, and S. Vassallo, "Urban Air Quality Monitoring Using Vehicular Sensor Networks", In Advances onto the Internet of Things, pp. 311-323, 2014.

[26] T. Ahuja, V. Jain, and S. Gupta, "Smart Pollution Monitoring for Instituting Aware Traveling", International Journal of Computer Applications, vol. 145, no. 9, pp. 0975-8887, July 2016.

[27] J. Vega, E. Varela, N. Romero, C. Santos, J. Cuevas, and D. Gorham, "Internet of Things (IoT) for Monitoring Air Pollutants with an Unmanned Aerial Vehicle (UAV) in a Smart City", Smart Technology, pp. 108-120. Springer, 2018.

[28] N. Husein, A. Rahman, and D. Dahnil, "Evaluation of LoRa-based Air Pollution Monitoring System", (IJACSA) International Journal of Advanced Computer Science and Applications, vol. 10, no. 7, 2019.

[29] M. Hossinuzzaman, and D. Dahnil, "Enhancement of Packet Delivery Ratio during Rain Attenuation for LoRa Technology", (IJACSA) International Journal of Advanced Computer Science and Applications, vol. 10, no. 10, 2019.

[30] D. Wijaya, R. Sarno, and E. Zulaika, "Gas concentration analysis of resistive gas sensor array", International Symposium on Electronics and Smart Devices (ISESD), pp. 337-342. IEEE, 2016.

[31] Kim, "Mq-8 Hydrogen/H2 Sensor Module", https://sandboxelectronics. com, p.196, 24 December 2019.

[32] A. Rahman, W. Jaafar, K. Maulud, N. Noor, M. Mohan, A. Cardil, C. Silva, N. Che'Ya, and N. Naba, "Applications of Drones in Emerging Economies: A case study of Malaysia", International Conference on Space Science and Communication (IconSpace), pp. 35-40. IEEE, 2019. 